\title{
Relationship Between Stock Market Returns and Macroeconomic Variables: Evidence from Turkey
}

\author{
Erhan Cankal \\ Yildirim Beyazit University, Business School, Ankara, Turkey \\ ecankal@ybu.edu.tr
}

\begin{abstract}
Financial sector is considered to be important in signaling about economic development. It is a common belief that stock market returns contain significant information on economic well-being and act as a good source of market indicator in a country. This common belief is tested for a number of countries using various methods in literature. Whether stock market returns are affected by changes in primary macroeconomic variables have been tested for different time periods in many countries. The findings of the previous studies proved that the results may vary depending on country specific characteristics. The directions and magnitudes of the examined relationships seemed to be different for various economies. However, the mainstream of the findings is consistent with theoretical expectations. This study attempts to bring a light to the relationship between stock market returns and basic macroeconomic variables using monthly data between 2003 and 2015 and employing structural vector autoregressive (SVAR) model for the Turkish economy. Turkey is considered as one of the most vulnerable five countries whose stock prices are most responsive to, exchange rate shocks. This study concludes that the stock prices in Turkey responsive to the shocks in exchange rate, interest rate, and inflation in order. The results of the analyses are in accordance with theoretical expectations as well as with the findings of the vast majority in the literature.
\end{abstract}

Keywords: Turkish Economy, Stock Market, Financial Sector, Macroeconomic Variables, SVAR Model

\section{Introduction}

It is well known that stock markets have been an important indicator of the financial sector in many countries. Potential and idle resources can be transfered into productive channels through financial instruments in an economy so that the economy can grow faster. Mostly, investors respond to the complexities of macroeconomic magnitudes and affect stock market performance. It is mostly perceived that stock markets and macroeconomic magnitudes are in close relationship. This leads to a number of researches on the subject in an effort to identify some possible interactions between stock returns and macroeconomic variables. Previous studies found controversial relationships between asset prices and primary macroeconomic variables. Understanding the factors that are effective on stock markets is crucial for investors, researches, and policy makers. That is why more studies are required to explore and clarify this subject. This research aims to investigate the relationship between stock market returns and some selected macroeconomic variables such as inflation, exchange rate, and interest rate using Structural Vector Autoregresive (SVAR) approach. This study will test the direction and magnitude of such relationships using monthly data for a certain time period. In this research, the macroeconomic variables are inflation, exchange rate, and interest rate, which are considered to be the most effective on the changes in stock market returns. Turkey is among the "Fragile Five" countries, which means, the stock market returns are most vulnerable to the exchange rate volatility. This study aims at testing the vulnerability of the stock prices to the shocks in the examined macroeconomic variables.

\section{Literature Review}

Kim and Roubini (2000) indicated that previous empirical studies on the effects of monetary policy found evidence of several anomalies. This study develops a solution to the empirical anomalies in an open economy using SVAR approach and identifies monetary policy shocks by modeling the reaction function of the monetary authorities. This paper emphasizes the success of SVAR approach in identifying monetary policy shocks and handling anomalies that arise from monetary policy shocks. The SVAR approach contributes to solving the price puzzle and exchange rate puzzles for non-U.S. industrial countries and provides evidence that delayed overshooting may not systematically occur. This study suggests including measures of fiscal policy to examine the effects of such shocks on nominal and real exchange rate. It is also suggested that fixed exchange rate periods are worth to examine in order to study the effectiveness of monetary policy during these periods such as the Bretton Woods periods. Bruneau and De Bandt 
(2003) showed that between January of 1979 and February of 2000 monetary shocks exhibit tight correlation while fiscal shocks are uncorrelated between France and Germany. The implication of SVAR models for Germany and France provides evidence that monetary policy shocks have a significant effect on the economy in contrary to fiscal policy. Fiscal shocks seemed to have no statistically significant effect on GDP and prices. Dungey and Fry (2009)'s research is an important contribution to the implication of SVAR to see the interaction of monetary and fiscal policies in New Zealand that has a history of long inflation targeting and well-constructed fiscal data set.

Chen et al. (1986) suggested that stock prices largely depend on the changes in macroeconomic variables that are vital in measuring economic performance of a country. Their findings reveal that some macroecomic variables such as unanticipated and expected inflation, interest rates, industrial production were significant determinants of stock prices. A number of studies investigated the relationship between stock market and industrial production. Hosseini et al. (2011) investigated the correlation between stock market indices and macroeconomic variables using monthly data from 1999 to 2009 for China and India. Their findings reveal opposite results for both countries. The long-run effect of crude oil price and money supply on China's stock returns is positive but negative on India's stock returns. Inflation was found to have a positive impact on stock returns for the countries. The study also shows that industrial production positively affects stock returns in India while it negatively affects in China.

Using the Turkish data and SVAR approach, Gökçe and Yiğit (2012) directed their research on the core inflation in the Turkish economy while Saraçoğlu et al. (2014) focused on the estimation of output gap. Saraçoğlu et al. (2014) asserted that output gap that is estimated by SVAR method produces better results in predicting actual inflation. Rad (2011) studied the relationship between Tehran Stock Exchange (TSE) price index and the macroeconomic variables such as consumer price index (CPI), liquidity (M2), exchange rate for 2001 - 2007 period using Unrestrictive Vector Autoregressive (VAR) model. The study concluded that selected macroeconomic factors are able to explain the part of volatility in asset prices. Some studies focused on the response of asset prices to oil price shocks. Rapidly increasing general price level of commodities causes a great tension in economies of both developing and developed countries. According to Hamilton $(1983,1996,2003)$ oil price shocks have been one of the significant factors of stock market returns. The changes in oil prices leads to direct and indirect effects on the prices of commodities and this may cause a fluctuation in stock market returns. Some of the studies such as in Culter, Poterba, and Summers (1989), Martinez and Rubio (1989), and Gjerde and Saettem (1999) suspected the presence of any significant relationships between macroeconomic variables and asset returns. Stock returns are also found to be incapable of capturing the full information of changes in macroeconomic variables for Asian markets (Fung and Lie, 1990).

Stock Market Returns and Macroeconomic Variables: Theoretical Background: It is common belief that stock market performance or returns can be better explained by the performances of macroeconomic variables. In fact, the stock market has been perceived as a secure instrument in observing economic situation. The selected macroeconomic variables for this research study are ISE100, Inflation Exchange Rate, Interest Rate that are viewed as important sources of variation in stock returns in Turkey. Hendry (1986), Maysami and Sim (2001a, 2001b, 2002) studied the effects of interest rates, inflation, exchange rate, and money supply on stock market returns and confirmed the effects of these macroeconomic variables on returns for Hong Kong, Singapore, Malaysia, Thailand, Japan, and South Korean stock markets. Mukherjee and Naka (1995) found long-run relationship between short-term interest rate, money supply and stock market returns in the same direction while a negative relationship between inflation, interest rate and stock market returns was found. However, some research papers (Culter et. al., 1989; Sims \& Schwert, 1989; Richards, 1996; Allen and Jagtianti, 1997) reported that they failed to find any significant evidence that the returns of stock markets are sensitive to changes in macroeconomic variables. This issue needs to be studied more in detail for different financial structure of a variety of countries.

ISE100 serves as the dependent variable and measures the returns of the stock market. It represents the closed prices of the stocks that are registered in Istanbul Stock Exhange Market. Inflation is a continuous increase in the general price level. Increases in inflation increase the cost of living and shift resources from investment to consumption thus reducing the demand for investments and assets. Therefore, a negative relationship between inflation and asset prices is hypothesized. Here, the wholesale price index of the Chamber of Istanbul is used as a proxy for inflation rate. Exchange Rate is the price of a currency in terms of other currency. In this study, an exchange rate which comprises of half U.S. Dollar and a half Euro 
is used as a proxy for exchange rate. Variations in the exchange rate affect the import demand and cost of production. This will lead to reduction in profits and cash flows and that is why it is anticipated a negative relationship between exchange rate and stock market returns. Interest rate is the opportunity cost of holding money. High interest rate increases the cost of borrowing and impacts investments negatively. The upward movement in interest rate puts a downward pressure in overall economic activities. Therefore, a negative relationship between interest rate and stock market returns are expected theoretically.

\section{Data and Methodolgy}

The data are monthly and extend from the January of 2003 to the April of 2015. The selected variables for analyses are exchange rate, interest rate, inflation, and ISE100 (Istanbul Stock Exchange Market) and are compiled using Turkish Central Bank electronic data distribution system. ISE100 represents Borsa100 closed prices. The inflation variable is calculated by taking the logarithmic first difference of the wholesale price index $(1968=100)$ of the Chamber of Istanbul. The exchange rate basket is comprised of $50 \%$ USD/TL and 50\% EUR/TL. The interest rate variable is a weighted interest rate that applied to monthly term deposits by banks. The stochastic properties of the series are examined before analyzing the impact of selected macroeconomic variables. Time series datum is stationary if the variance and average values are constant in the examined period and covariance values between any two time spots depend on the time lag between these time spots. Stationary is necessary in order to generate reliable results and so valid interpretation (Granger and Newbold, 1974; Phillips, 1986). The stationarity tests are conducted in order to examine the time series properties of the variables. Here, ADF (Dickey and Fuller, 1981), PP (Phillips and Perron, 1988), and KPSS (Kwiatkowski, Phillips, Schmidt and Shin, 1992) tests are performed for stationarity. The results of these tests are summarized in Table 1. The results in Table 1 are documented for level and first differences of the variables of ISE100 index values and the natural logarithms of the exchange rate.

Table 1: Unit Roots Test for Stationary

\begin{tabular}{llllllll}
\hline Variables & ADF & PP & $\begin{array}{l}\text { KPSS- } \\
\mathbf{L M}\end{array}$ & Variables & ADF & PP & $\begin{array}{l}\text { KPSS- } \\
\mathbf{L M}\end{array}$ \\
\hline lnISE100 & -1.9210 & 1.7170 & $0.1640^{* *}$ & $\Delta$ lnBíST100 & -9.3033 & -9.3772 & 0.1253 \\
& {$[0.3220]$} & {$[0.9791]$} & & & {$[0.0000]$} & {$[0.0000]$} & \\
Inflation & -7.9171 & -7.4877 & 0.1345 & $\Delta$ Inflation & -9.3740 & -34.2727 & 0.2528 \\
InExchange & {$[0.0000]$} & {$[0.0000]$} & & & {$[0.0000]$} & {$[0.0001]$} & \\
Rate & 1.3278 & 1.4849 & $0.2914^{*}$ & $\Delta$ lnExchange & -8.9544 & -8.9468 & 0.2090 \\
Interest Rate & {$[0.9533]$} & {$[0.9658]$} & & Rate & {$[0.0000]$} & {$[0.0000]$} & \\
& -4.8303 & -5.1273 & $0.2023^{* *}$ & $\Delta$ Interest rate & -7.9011 & -7.8677 & 0.1370 \\
\hline
\end{tabular}

Notes: The test statistics of the optimal model are given based on Schwarz information criteria. The numbers in brackets are p-values. For ADF and PP tests $\mathrm{H}_{0}$ : series have unit root. For KPSS $\mathrm{H}_{0}$ : series are stationary. $\mathrm{H}_{0}$ is rejected at ${ }^{*} 1 \%,{ }^{* *} 5 \%$ and ${ }^{* * *} 10 \%$ significance levels.

The findings in Table 1 point out that the inflation variable is stationary at level based on the results of the three testing procedures. On the other side, the interest rate variable is stationary at level based on ADF and PP tests but is non-stationary based on KPSS test. Here, the interest rate variable is assumed to be stationary at level because the two test results confirmed its stationarity. InISE100 and InExchange Rate variables are non-stationary at level based on the three tests performed. The variables that are nonstationary at level are confirmed to be stationary at first difference. Thus the series InISE100 and lnExchange Rate are individually integrated of order one I(1) except for Inflation and Interest Rate which are I(0). In this study, the relationship between ISE100 monthly returns and inflation, exchange rate monthly return, interest rate will be examined. Inflation and interest rate will be included at level while the lnISE100 and InExchange Rate will be included at their first differences.

\section{SVAR Estimates and Empirical Results}

Sims (1980) proposed the use of VAR models when conducting economic research. A number of implications of the model has investigated oil price and macroeconomy interaction, stock prices and industrial production, stock prices and macroeconomic variables. Hamilton (1983), Burbidge and 
Harrison (1984), Ahmed and Wadud (2011), and Park et al. (2011) have used VAR approach to examine macroeconomic magnitudes and oil price relationship. The SVAR model is employed to estimate dynamic long-run effects of the selected macroeconomic variables on stock market compounded index returns. Therefore, the dynamic effects of the variables on each other are examined conveniently as bivariate instead of as a whole. The purpose of this is to eliminate the effects of the variables on each other (multicollinearity). The relations that will be examined depending on the VAR model ordering are inflation-ISE100, Exchange rate return - ISE100 return, and interest rate - ISE100 return. In order to obtain SVAR estimations, initially, the bivariate unrestricted VAR model should be constructed and optimal lag length should be determined. Tables 2, 3, and 4 show estimated unrestricted VAR model optimal lag length for inflation-BIST100 return, exchange rate-ISE100 return and interest rate-ISE100 return respectively. The relevant analyses have been carried out by employing the software package of EVIEWS.

Table 2: VAR Lag Order Selection Criteria

\begin{tabular}{llllll}
\hline Lag & LR & FPE & AIC & SC & HQ \\
\hline 0 & NA & 32.52608 & 9.157793 & 9.238799 & 9.190706 \\
$\mathbf{1}$ & $\mathbf{4 0 . 5 4 9 7 1 *}$ & $\mathbf{2 5 . 9 0 7 2 8 *}$ & $\mathbf{8 . 9 3 0 2 5 2 *}$ & $\mathbf{9 . 0 9 2 2 6 3}$ & $\mathbf{8 . 9 9 6 0 7 7 ^ { * }}$ \\
2 & 2.034139 & 26.95896 & 8.969981 & 9.212998 & 9.068718 \\
3 & 6.958650 & 27.07978 & 8.974330 & 9.298353 & 9.105980 \\
4 & 2.798757 & 28.01561 & 9.008104 & 9.413132 & 9.172666 \\
5 & 4.159070 & 28.68963 & 9.031576 & 9.517611 & 9.229051 \\
6 & 2.597818 & 29.71418 & 9.066244 & 9.633284 & 9.296631 \\
7 & 4.301965 & 30.37590 & 9.087707 & 9.735753 & 9.351007 \\
8 & 3.852288 & 31.14938 & 9.112128 & 9.841180 & 9.408340 \\
\hline
\end{tabular}

${ }^{*}$ Indicates lag order selected by the criterion. LR: Likelihood Ratio, FPE: Final Prediction Error, AIC: Akaike Information Criteria, SCI: Schwarz Information Criteria, HQ: Hannan-Quinn Criteria.

Table 3: VAR Lag Order Selection Criteria

\begin{tabular}{llllll}
\hline Lag & LR & FPE & AIC & SC & HQ \\
\hline 0 & NA & 368.6276 & 11.58554 & 11.66654 & 11.61845 \\
1 & $\mathbf{8 9 . 7 6 7 9 0 *}$ & 208.6119 & 11.01620 & $\mathbf{1 1 . 1 7 8 2 2}^{*}$ & $\mathbf{1 1 . 0 8 2 0 3 *}$ \\
$\mathbf{2}$ & 9.175991 & $\mathbf{2 0 6 . 4 3 2 3}$ & $\mathbf{1 1 . 0 0 5 6 4 *}$ & 11.24866 & 11.10438 \\
3 & 4.335596 & 211.2792 & 11.02872 & 11.35275 & 11.16037 \\
4 & 4.988929 & 215.1390 & 11.04663 & 11.45165 & 11.21119 \\
5 & 3.065340 & 222.0938 & 11.07814 & 11.56418 & 11.27562 \\
6 & 3.618990 & 228.2788 & 11.10519 & 11.67223 & 11.33557 \\
7 & 6.054958 & 230.2839 & 11.11337 & 11.76142 & 11.37667 \\
8 & 6.579501 & 231.2453 & 11.11681 & 11.84586 & 11.41302 \\
\hline
\end{tabular}

${ }^{*}$ Indicates lag order selected by the criterion. LR: Likelihood Ratio, FPE: Final Prediction Error, AIC: Akaike Information Criteria, SCI: Schwarz Information Criteria, HQ: Hannan-Quinn Criteria.

Table 4: VAR Lag Order Selection Criteria

\begin{tabular}{llllll}
\hline Lag & LR & FPE & AIC & SC & HQ \\
\hline 0 & NA & 3214.329 & 13.75112 & 13.83213 & 13.78404 \\
1 & 711.0729 & 24.32354 & 8.867172 & 9.029184 & 8.932997 \\
$\mathbf{2}$ & $\mathbf{2 3 . 1 8 6 5 6 *}$ & $\mathbf{2 1 . 8 0 7 9 7 *}$ & $\mathbf{8 . 7 5 7 9 4 1 *}$ & $\mathbf{9 . 0 0 0 9 5 8 *}$ & $\mathbf{8 . 8 5 6 6 7 8 *}$ \\
3 & 3.432423 & 22.46446 & 8.787477 & 9.111500 & 8.919127 \\
4 & 7.313053 & 22.49283 & 8.788538 & 9.193567 & 8.953101 \\
5 & 4.401399 & 22.99297 & 8.810229 & 9.296264 & 9.007704 \\
6 & 7.517315 & 22.95566 & 8.808184 & 9.375224 & 9.038571 \\
7 & 2.967433 & 23.70533 & 8.839757 & 9.487803 & 9.103057 \\
8 & 4.134299 & 24.25627 & 8.862009 & 9.591061 & 9.158221 \\
\hline
\end{tabular}

${ }^{*}$ Indicates lag order selected by the criterion. LR: Likelihood Ratio, FPE: Final Prediction Error, AIC: Akaike Information Criteria, SCI: Schwarz Information Criteria, HQ: Hannan-Quinn Criteria.

Considering Schwarz information criteria with parsimonious, VAR models optimum lag length is determined Table 2 for inflation-ISE100 return, and Table 3 for exchange rate return-ISE100 return, and Table 4 for interest rate-ISE100 return. The heteroscedasticity is observed in the VAR model residuals for inflation-ISE100 at lag length 1 in VAR model residuals and this problem vanished at lag length 2. Based 
on this, VAR(2) model is convenient for all pair of variables. VAR residual Portmanteau tests for autocorrelation indicates no autocorrelation up to 12 months lag. White heteroscedasticity test shows no heteroscedasticity in residuals. VAR model will be within unit circle if inverse roots of AR characteristic is polynomial. The VAR residuals multivariate normality test is performed using structural factorization and the null hypothesis that assumes normality is accepted. These stability test results are tabulated and shown in appendix 1 for inflation-ISE100, and in appendix 2 for exchange rate-ISE100, and in appendix for interest rate-ISE100. Structural moving average (SMA) representation for SVAR estimations can be shown with bivariate system equation (1).

$$
\left[\begin{array}{l}
y_{1 t} \\
y_{2 t}
\end{array}\right]=\left[\begin{array}{l}
\mu_{1} \\
\mu_{2}
\end{array}\right]=\left[\begin{array}{ll}
\theta_{11}^{(0)} & \theta_{12}^{(0)} \\
\theta_{21}^{(0)} & \theta_{22}^{(0)}
\end{array}\right]\left[\begin{array}{l}
\varepsilon_{1 t} \\
\varepsilon_{2 t}
\end{array}\right]+\left[\begin{array}{ll}
\theta_{11}^{(1)} & \theta_{12}^{(1)} \\
\theta_{21}^{(1)} & \theta_{22}^{(1)}
\end{array}\right]\left[\begin{array}{l}
\varepsilon_{1 t-1} \\
\varepsilon_{2 t-1}
\end{array}\right]+\cdots
$$

where $\theta_{i j}^{(k)}$ gives the dynamic multipliers or impulse responses of $y_{1 t}$ and $y_{2 t}$ to changes in $\varepsilon_{1 t}$ and $\varepsilon_{2 t}$.

Here, $y_{1 t}$ represents inflation, exchange rate, and interest rate respectively, and $y_{2 t}$ represents BIST returns. The SVAR estimations will be renewed for each pair of variables. SMA representation can be employed for SVAR model impulse-response functions. The long-run accumulated impact of the structural shocks is captured by the long-run impact matrix

$$
\boldsymbol{\Theta}(L)=\left[\begin{array}{ll}
\theta_{11}(L) & \theta_{12}(L) \\
\theta_{21}(L) & \theta_{22}(L)
\end{array}\right]=\left[\begin{array}{cc}
\sum_{s=0}^{\infty} \theta_{11}^{(s)} L^{s} & \sum_{s=0}^{\infty} \theta_{12}^{(s)} L^{s} \\
\sum_{s=0}^{\infty} \theta_{21}^{(s)} L^{s} & \sum_{s=0}^{\infty} \theta_{22}^{(s)} L^{s}
\end{array}\right] .
$$

Structural VAR models require imposing some restrictions on the system of equations to retrieve the structural shocks. In other words, we must use economic intuition to identify the parameters and the shocks of the structural model. Blanchard and Quah (1989) proposed an alternative identification method based on restrictions on the long-run properties of the impulse responses. Identification of the parameters of the SVAR is achieved through restrictions on the parameters of the SMA representation. The exogenous error terms $\varepsilon_{1 t}$ and $\varepsilon_{2 t}$ are independent and are interpreted as structural innovations. Realizations of $\varepsilon_{1 t}$ are interpreted as capturing unexpected shocks to inflation, exchange rate return and the rate of change in interest rate that are uncorrelated with the unexpected shocks to ISE100 return. In this study, it is assumed that the cumulative response to a structural shock of ISE100 on inflation, exchange rate return and interest rate to be zero in the long-run. When considering this restriction with equation (2), it can be written as $\theta_{12}(1)=\sum_{s=0}^{\infty} \theta_{12}^{(s)}=0$ and it is meaningful in economic sense. In this case, the long run impact matrix $\boldsymbol{\Theta}(1)$ becomes triangular.

$$
\boldsymbol{\Theta}(1)=\left[\begin{array}{cc}
\theta_{11}(1) & 0 \\
\theta_{21}(1) & \theta_{22}(1)
\end{array}\right] \text {. }
$$

In order to take breaks in ISE100 into account, a dummy variable is defined by assigning the value of 1 for 2006.M05, 2008.M09, and 2013.M05 periods and 0 for other periods. This dummy variable is employed as an exogeneous variable in VAR estimations.

Table 5: SVAR Estimates ${ }^{a}$

\begin{tabular}{ll}
\hline Relations & Long-term parameter \\
\hline Inflation-BIST100 return & -1.7625 \\
& $(-2.8055)$ \\
Exchange Rate-BİST100 return & {$[0.0050]$} \\
& -4.4426 \\
& $(-7.3255)$ \\
Interest rate-BİST100 return & {$[0.0000]$} \\
& -1.7738 \\
& $(-2.9531)$ \\
\hline
\end{tabular}

a The numbers in paranthesis are z-statistics, p-values are in brackets. 
The estimated results in Table 5 enable to extract some interesting remarks. According to the findings, the accumulated response of ISE100 returns in long-run accross a structural shock in inflation is -1.7625 points. So, monthly BIST return decreases by 1.7625 points. Similarly, as a response to a shock in exchange rate and interest rate, the accumulated long-run response of the ISE100 return will be -4.4426 and -1.7738 respectively. These responses are highly significant statistically. Another attention drawing point here is that the response of stock returns to fluctuations in exchange rate is considerably higher when compared to that of other variables. When these responses are in descending order, it follows a rank of exchange rate, interest rates, and inflation. The signs of responses are negative as expected. Structural decomposition uses the orthogonal transformation that is estimated from the structural factorization matrices. At this stage, forecast error variance decompositions measure the contribution of each type of shock to the forecast error variance. In other words, it determines how much of the forecast error variance of each of the variables can be explained by exogenous shocks to the other variables and enables to have important information about the dynamic structure of the system. This computation is handy in assessing how shocks to economic variables reverberate through a system. Table 6 , Table 7 , and Table 8 show variance decomposition results for inflation, exchange rate, and interest rate shocks respectively. The exchange rate shocks seem to be the main source of variation in ISE100 returns. The contribution of the exchange rate shocks to the forecast error variance of ISE100 returns is approximately $44.81 \%$ while those of the interest rate shocks and the inflation rate shocks are $22.41 \%$ and $4.78 \%$ respectively.

Table 6: Structural Variance Decomposition of ISE100 Returns for Inflation Shock

\begin{tabular}{lccc}
\hline Period & Standart Error & Inflation Shock & ISE100 Returns Shock \\
\hline 1 & 6.813419 & 2.846988 & 97.15301 \\
2 & 7.030290 & 4.663878 & 95.33612 \\
3 & 7.044484 & 4.656280 & 95.34372 \\
4 & 7.048053 & 4.745057 & 95.25494 \\
5 & 7.049221 & 4.776389 & 95.22361 \\
6 & 7.049387 & 4.780543 & 95.21946 \\
7 & 7.049396 & 4.780741 & 95.21926 \\
8 & 7.049397 & 4.780741 & 95.21926 \\
9 & 7.049397 & 4.780745 & 95.21926 \\
10 & 7.049397 & 4.780746 & 95.21925 \\
\hline
\end{tabular}

Table 7: Structural Variance Decomposition of ISE100 Returns for Exchange Rate Shock

\begin{tabular}{lccc}
\hline Period & Standart Error & Exchange Rate Shock & ISE100 Returns Shock \\
\hline 1 & 2.275561 & 46.26613 & 53.73387 \\
2 & 3.022355 & 44.80462 & 55.19538 \\
3 & 3.098546 & 44.76732 & 55.23268 \\
4 & 3.106564 & 44.80005 & 55.19995 \\
5 & 3.108233 & 44.80901 & 55.19099 \\
6 & 3.108537 & 44.80820 & 55.19180 \\
7 & 3.108672 & 44.80810 & 55.19190 \\
8 & 3.108683 & 44.80810 & 55.19190 \\
9 & 3.108686 & 44.80810 & 55.19190 \\
10 & 3.108686 & 44.80810 & 55.19190 \\
\hline
\end{tabular}

Table 8. Structural Variance Decomposition of ISE100 Returns

\begin{tabular}{llll}
\hline Period & Standart Error & Interest Rate Shock & ISE100 Returns Shock \\
\hline 1 & 6.827417 & 23.26415 & 76.73585 \\
2 & 7.006251 & 22.42886 & 77.57114 \\
3 & 7.021419 & 22.33486 & 77.66514 \\
4 & 7.023190 & 22.35301 & 77.64699 \\
5 & 7.024025 & 22.37122 & 77.62878 \\
6 & 7.024580 & 22.38342 & 77.61658 \\
7 & 7.024981 & 22.39219 & 77.60781 \\
8 & 7.025298 & 22.39916 & 77.60084 \\
9 & 7.025566 & 22.40505 & 77.59495 \\
10 & 7.025798 & 22.41018 & 77.58982 \\
\hline
\end{tabular}


One of the interesting findings of the VAR model is the graphs of impulse-response functions. The effect of a unit shock in one of the error terms in VAR model on the current and future values of the endogeneous variables can be observed through these functions. In this context, the cumulative response of ISE100 returns to the shocks are presented in graphs. In the graphs, the cumulative responses of ISE100 returns to inflation, exchange rate, and interest rate shocks are shown. The response of ISE100 to the all mentioned shocks is negative, or in other words, ISE100 returns have tendency to move downward. The ISE100 returns keep downward movement for 5-month period as a response to a shock in exchange rate. The cumulative negative movement arised by the inflation shock lasts 2 months and vanishes after 5 months. The negative effect of the interest rate shock is eliminated faster than other shocks. The interest rate shock dies out following 2-months period. The significant finding here is that the exhange rate has the strongest downward effect on ISE100 returns, which is consistent with the results of the variance decomposition. The ISE100 index is the most responsive to the changes in exchange rate in Brasil, India, Indonesia, South Africa, and Turkey, which is called "Fragile Five" by Morgan Stanley. This result verifies that Turkey is one of the five countries that the stock return is most vulnerable to exchange rate volatility. The impulse-response graphs are given in Figure 1.

\section{Figure 1 (a)}

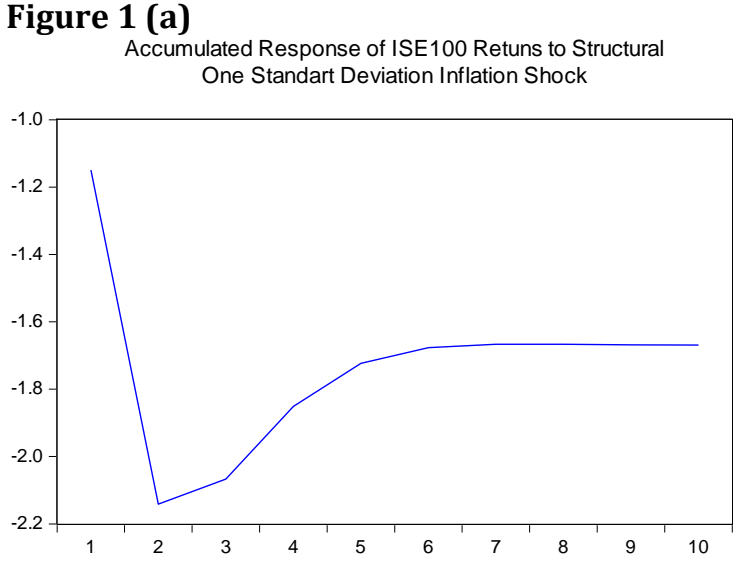

(b)

Accumulated Response of ISE100 Returns to Structural One Standart Deviation Basket

(c)

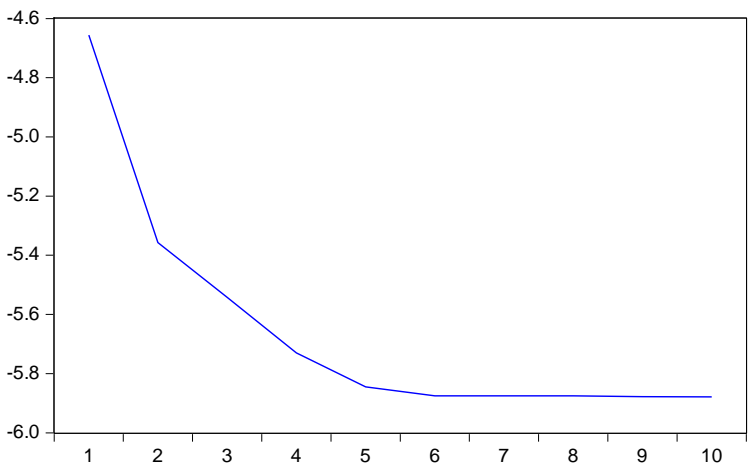

Accumulated Response of ISE100 Returns to Structural One Standart Deviation Interest Rate

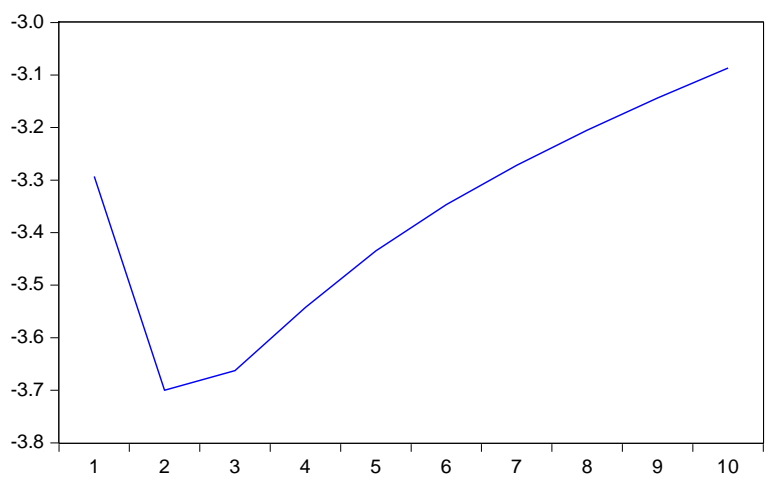




\section{Conclusion}

The relationship between stock market returns and macroeconomic variables has been an important topic for both academicians and finance practitioners. Most studies have been performed for developed economies. Whether the research is about a developed or an emerging market might be important because of the exposure of the market to globall or local risk factors. Some of the findings have proven the existence of relationship between stock prices and macroeconomic magnitudes while some other studies have failed to support such relationship. This study reveals that the response of the stock market returns to exchange rate is found to be remarkably greater in magnitude than other selected macroeconomic variables, following interest rate and inflation respectively. The estimated signs show negative relationship between the stock prices and the examined macroeconomic variables as initially expected. This study proves the relationship between stock prices and exchange rate, interest rate, and inflation in different degrees of sensitivity for the examined period in Turkey. The higher cost of living because of inflation leads to a decline in resources that is allocated for investment and instead increases consumption. Therefore, a decline in incentive for investment puts a downward pressure on the stock market returns. This results are in accordance with theoretical expectation but it should be kept in mind that there are findings contrary of this perception in the literature as well. It seemed that the expected relationships between stock market returns and macroeconomic variables may vary depending on economic and financial structure in a country. The responsiveness of stock markets to variations in macroeconomic variables is also a significant factor in evaluating such a relationship for an economy. Since Turkey is considered as one of the five countries whose stock prices are most vulnerable to exchange rate changes, the findings of this study verify this statement. ISE100 index is the most responsive to the shocks in exchange rate and to the shocks in interest rate and inflation in order. The SVAR results, the magnitude of the parameters, the results of variance decomposition and impulseresponse analyses are all consistent with each other and theoretical expectations. The results of the study are expected to contribute to the related literature from Turkey's perspective. However, the controversy of the findings for various countries in the relevant literature contradicts with the view that the stock market is a reliable economic instrument to observe economic progress. That is why more research studies are required to further explore this topic.

\section{References}

Ahmed, H. J. A. \& Wadud, M. I. K. M. (2011). Role of Oil Price Shocks on Macroeconomic Activities: An SVAR Approach to the Malaysian Economy and Monetary Responses. Energy Policy, 39, 8062806.

Allen, L. \& Jagtianti, J. (1997). Risk and Market Segmentation in Financial Intermediaries' Returns. Journal of Financial Service Research, 12, 159-173.

Blanchard, O. J. \& Quah, D. (1989). The Dynamic Effects of Aggregate Demand and Supply Disturbances. American Economic Review, 79, 1146-64.

Bruneau, C. \& De Bandt, O. (2003). Monetary and Fiscal Policy in the transition to EMU: What do SVAR models tell us? Economic Modelling, 20, 959-985.

Burbidge, J. \& Harrison, A. (1984). Testing for the Effects of Oil-Price Rises Using Vector Autoregressions. International Economic Review, 25(2), 459-484.

Chen N. F., Roll R. \& Ross S. A. (1986). Economic Forces and the Stock Market. Journal of Business, 59, 383403.

Culter, D. M., Poterba, J. M. \& Summers, L. H. (1989). What Moves Stock Prices? Journal of Portfolio Management, 15, 4-12.

Dickey, D. A. \& Fuller, W. A. (1979). Distribution of the Estimators for Autoregressive Time Series with a Unit Root. Journal of American Statistical Society, 75, 427-431.

Dungey, M. \& Fry, R. (2009). The Identification of Fiscal and Monetary Policy in a Structural VAR. Economic Modelling, 26, 1147-1160.

Fung H. G. \& Lie, C. J. (1990). Stock Market and Economic Activities: A Causal Analysis. Pacific-Basin Capital Markets Research, Amsterdam.

Gjerde, O. \& Saettem, F. (1999). Causal Relations among Stock Returns and Macroeconomic Variables in a Small, Open Economy. Journal of International Finance Markets Institutions and Money, 9, 61-74.

Gökçe, A. \& Yiğit, Ö. (2012). Türkiye'de Çekirdek Enflasyon: Ekonometrik Bir Yaklaşım. Central Bank Review, 12, 37-51.

Granger, C. W. J. \& Newbold, P. (1974). Spurious Regressions in Econometrics. Journal of Econometrics, 2, 111-120. 
Hamilton, J. D. (1983). Oil and the Macro Economy since World War II. Journal of Political Economy, 228248.

Hamilton, J. D. (1996). This is What Happened to the Oil-Macroeconomy Relationship. Journal of Monetary Economics, 2, 215-220.

Hamilton, J. D. (2003). What is an Oil Shock? Journal of Econometrics, 2, 363-398.

Hendry, D. F. (1986). Econometric Modeling with Cointegrated Variables: an overview. Oxford Bulletin of Economics and Statistics, 48, 201-212.

Hosseini, S. M., Ahmad, Z. \& Lai, Y. W. (2011). The Role of Macroeconomic Variables on Stock Market Index in China and India. International Journal of Economics and Finance, 3(6), 233-243. http://dx.doi.org/10.5539/ijef.v3n6p233.

Kim, S. \& Roubini, N. (2000). Exchange Rate Anomalies in the Industrial Countries: A Solution with a Structural VAR Approach. Journal of Monetary Economics, 45, 561-586.

Kwiatkowski, D., Phillips, P. C. B., Schmidt, P. \& Shin, Y. (1992). Testing the Null-Hypothesis of Stationary against the Alternative of a Unit Root. Journal of Econometrics, 54, 159-178.

Lee, B. S. (1992). Causal Relations among Stock Returns, Interest Rates, Real Activity and Modelinflation. Journal of Finance, 47, 1591-1603.

Martinez, M. A. \& Rubio, G. (1989). Arbitrage Pricing with Macroeconomic Variables: An Empirical Investigation using Spanish Data. Working Paper, Universidad del Pais Vasco.

Maysami, R. C. \& Sim, H. H. (2001a). An Emprirical Investigation of the Dynamic Relations between Macroeconomic Variable and the Stock Markets of Malaysia and Thailand. Jurnal Pengurusan, 1, $1-20$.

Maysami, R. C. \& Sim, H. H. (2001b). Macroeconomic Forces and Stock Returns: A General-to-Specific ECM Analysis of the Japanese and South Korean Markets. International Quarterly Journal of Finance, 1, 83-99.

Maysami, R. C. \& Sim, H. H. (2002). Macroeconomic Variables and Their Relationship with Stock Returns: Error Correction Evidence from Hong Kong and Singapore. The Asian Economic Review, 44, 69-85.

Mukherjee, T. K. \& Naka A. (1995). Dynamic Relations between Macroeconomic Variables and the Japanese Stock Market: An Application of a Vector Error Correction Model. Journal of Financial Research, 18, 223-237.

Park, C., Chung, M. \& Lee, S. (2011). The Effects of Oil Price on Regional Economies with different Production Structures: A case study from Korea using a Structural VAR Model. Energy Policy, 39, 8185-8195.

Phillips, P. C. B. (1986). Understanding Spurious Regressions in Econmetrics. Journal of Econometrics, 33(3), 311-340.

Phillips, P. C. B. \& Perron, P. (1988). Testing for a unit root in time series regressions. Biometrica, 75, 335346.

Rad, A. A. (2011). Macroeconomic Variables and Stock Market Evidence from Iran. International Journal of Economics and Finance Studies, 3(1), 1-10.

Richards, A. J. (1996). Volatility and Predictability in National Stock Markets: How Do Emerging Markets Differ? Internationally Monetary Fund Staff Papers, 42, 461-501.

Saraçoğlu, B., Yiğit, Ö. \& Koçak, N. A. (2014). Alternative Methods of Estimating Output Gap for Turkey. Business and Economics Research Journal, (5), 3, 43-65.

Sevuktekin, M. \& Nargelecekenler, M. (2005). Zaman Serisi Analizi. Nobel Yayin Dagitim, İzmir (in Turkish).

Sims, J. (1980). Macroeconomics and Reality. Econometrica, 48, 1-48.

Sims, J. \& Schwert, W. G. (1989). Why Does Stock Market Volatility Change over Time? Journal of Finance, 44, 1115-1153. 
Apendix 1: Results of VAR Residual Portmanteau Tests for Autocorrelations

\begin{tabular}{llllll}
\hline Lags & Q-Stat & Prob. & Adj Q-Stat & Prob. & df \\
\hline 1 & 0.187336 & $\mathrm{NA}^{*}$ & 0.188610 & $\mathrm{NA}^{*}$ & $\mathrm{NA}^{*}$ \\
2 & 1.118001 & $\mathrm{NA}^{*}$ & 1.132024 & $\mathrm{NA}^{*}$ & $\mathrm{NA}^{*}$ \\
3 & 2.273298 & 0.6856 & 2.311224 & 0.6787 & 4 \\
4 & 6.333516 & 0.6099 & 6.484225 & 0.5932 & 8 \\
5 & 9.227515 & 0.6834 & 9.479413 & 0.6615 & 12 \\
6 & 14.73176 & 0.5444 & 15.21623 & 0.5089 & 16 \\
7 & 20.47504 & 0.4286 & 21.24464 & 0.3829 & 20 \\
8 & 25.06733 & 0.4021 & 26.09935 & 0.3481 & 24 \\
9 & 25.70270 & 0.5894 & 26.77586 & 0.5305 & 28 \\
10 & 29.41426 & 0.5981 & 30.75636 & 0.5294 & 32 \\
11 & 32.59519 & 0.6313 & 34.19270 & 0.5547 & 36 \\
12 & 42.35985 & 0.3695 & 44.81895 & 0.2768 & 40 \\
\hline
\end{tabular}

*Null Hypothesis: No residual autocorrelations up to lag 12.

Results of VAR Residual Heteroskedasticity Tests

\section{Joint test:}

Chi-sq df Prob

$31.23222 \quad 27 \quad 0.2617$

Individual components:

\begin{tabular}{llllll} 
Dependent & R-squared & $\mathrm{F}(9,138)$ & Prob. & Chi-sq(9) & Prob. \\
res1*res1 & 0.060380 & 0.985313 & 0.4550 & 8.936177 & 0.4432 \\
res2*res2 & 0.067849 & 1.116080 & 0.3555 & 10.04169 & 0.3471 \\
res2*res1 & 0.087446 & 1.469318 & 0.1652 & 12.94195 & 0.1653 \\
\hline
\end{tabular}

*Null Hypothesis: No heteroscedastity

Results of VAR Residual Normality Tests

\begin{tabular}{lllll}
\hline Component & Skewness & Chi-sq & df & Prob. \\
\hline 1 & -0.179923 & 0.798520 & 1 & 0.3715 \\
2 & -0.024076 & 0.014298 & 1 & 0.9048 \\
Joint & & 0.812818 & 2 & 0.6660 \\
Component & Kurtosis & Chi-sq & df & Prob. \\
1 & 3.655081 & 2.646311 & 1 & 0.1038 \\
2 & 2.530055 & 1.361897 & 1 & 0.2432 \\
Joint & & 4.008208 & 2 & 0.1348 \\
Component & Jarque-Bera & df & Prob. & \\
1 & 3.444831 & 2 & 0.1786 & \\
2 & 1.376196 & 2 & 0.5025 & \\
Joint & 4.821026 & 4 & 0.3062 & \\
\hline
\end{tabular}

*Null Hypothesis: Residuals are multivariate normal 
Inverse Roots of AR Characteristic Polynomial

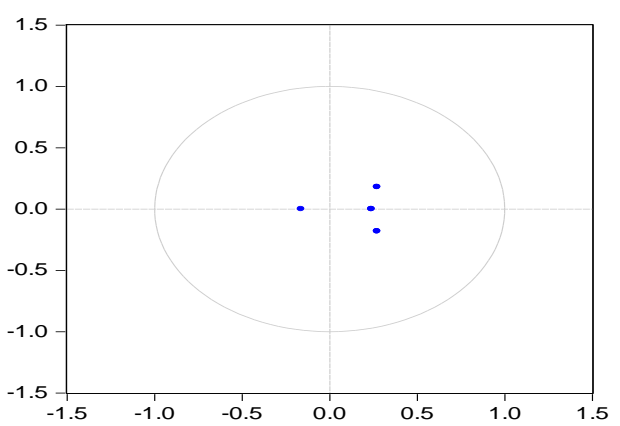

Appendix 2: Results of VAR Residual Portmanteau Tests for Autocorrelations

\begin{tabular}{llllll}
\hline Lags & Q-Stat & Prob. & Adj Q-Stat & Prob. & Df \\
\hline 1 & 1.989105 & $\mathrm{NA}^{*}$ & 2.002636 & $\mathrm{NA}^{*}$ & $\mathrm{NA}^{*}$ \\
2 & 3.296575 & $\mathrm{NA}^{*}$ & 3.328017 & $\mathrm{NA}^{*}$ & $\mathrm{NA}^{*}$ \\
3 & 7.788124 & 0.0997 & 7.912494 & 0.0948 & 4 \\
4 & 8.439341 & 0.3918 & 8.581801 & 0.3788 & 8 \\
5 & 13.34910 & 0.3442 & 13.66323 & 0.3227 & 12 \\
6 & 14.13875 & 0.5884 & 14.48625 & 0.5625 & 16 \\
7 & 19.85855 & 0.4668 & 20.49000 & 0.4277 & 20 \\
8 & 23.64226 & 0.4822 & 24.48993 & 0.4339 & 24 \\
9 & 27.02853 & 0.5167 & 28.09545 & 0.4594 & 28 \\
10 & 31.38119 & 0.4977 & 32.76352 & 0.4294 & 32 \\
11 & 32.04943 & 0.6570 & 33.48541 & 0.5888 & 36 \\
12 & 41.22974 & 0.4166 & 43.47576 & 0.3256 & 40 \\
\hline
\end{tabular}

*Null Hypothesis: No residual autocorrelations up to lag 12.

Results of VAR Residual Heteroskedasticity Tests

\begin{tabular}{llllll}
\hline $\begin{array}{l}\text { Joint test: } \\
\text { Chi-sq }\end{array}$ & df & Prob. & & & \\
\hline 35.36462 & 27 & 0.1299 & & & \\
Individual components: & & & & \\
Dependent & R-squared & F(9,138) & Prob. & Chi-sq(9) & Prob. \\
res1*res1 & 0.142922 & 2.556901 & 0.0095 & 21.15240 & 0.0120 \\
res2*res2 & 0.048345 & 0.778955 & 0.6361 & 7.155119 & 0.6210 \\
res2*res1 & 0.030521 & 0.482715 & 0.8843 & 4.517042 & 0.8742 \\
\hline
\end{tabular}

*Null Hypothesis: No heteroscedastity

Results of VAR Residual Normality Tests

\begin{tabular}{lllll}
\hline Component & Skewness & Chi-sq & df & Prob. \\
\hline 1 & 0.298636 & 2.199862 & 1 & 0.1380 \\
2 & -0.185577 & 0.849487 & 1 & 0.3567 \\
Joint & & 3.049349 & 2 & 0.2177 \\
Component & Kurtosis & Chi-sq & df & Prob. \\
1 & 3.473318 & 1.381518 & 1 & 0.2398 \\
2 & 2.923066 & 0.036499 & 1 & 0.8485 \\
Joint & & 1.418017 & 2 & 0.4921 \\
Component & Jarque-Bera & Df & Prob. & \\
1 & 3.581380 & 2 & 0.1668 & \\
2 & 0.885986 & 2 & 0.6421 & \\
Joint & 4.467366 & 4 & 0.3464 & \\
\hline
\end{tabular}

* Null Hypothesis: Residuals are multivariate normal 


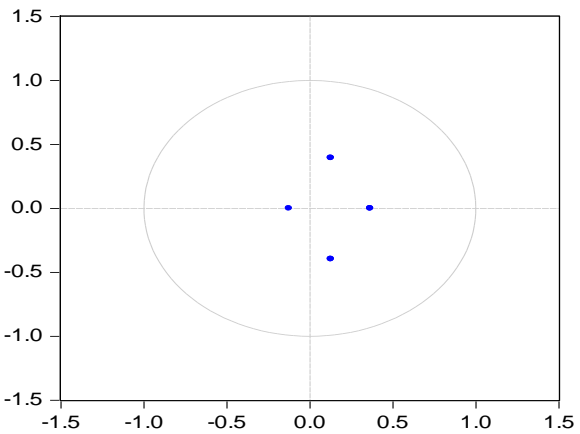

Appendix 3: Results of VAR Residual Portmanteau Tests for Autocorrelations

\begin{tabular}{llllll}
\hline Lags & Q-Stat & Prob. & Adj Q-Stat & Prob. & Df \\
\hline 1 & 1.562774 & $\mathrm{NA}^{*}$ & 1.573406 & $\mathrm{NA}^{*}$ & $\mathrm{NA}^{*}$ \\
2 & 1.839721 & $\mathrm{NA}^{*}$ & 1.854146 & $\mathrm{NA}^{*}$ & $\mathrm{NA}^{*}$ \\
3 & 4.726960 & 0.3165 & 4.801121 & 0.3083 & 4 \\
4 & 6.174160 & 0.6277 & 6.288521 & 0.6149 & 8 \\
5 & 12.64234 & 0.3956 & 12.98286 & 0.3703 & 12 \\
6 & 13.58867 & 0.6293 & 13.96917 & 0.6010 & 16 \\
7 & 17.56561 & 0.6160 & 18.14356 & 0.5780 & 20 \\
8 & 20.27697 & 0.6809 & 21.00985 & 0.6381 & 24 \\
9 & 33.06808 & 0.2332 & 34.62916 & 0.1809 & 28 \\
10 & 35.53744 & 0.3052 & 37.27746 & 0.2392 & 32 \\
11 & 42.62373 & 0.2076 & 44.93272 & 0.1460 & 36 \\
12 & 49.09945 & 0.1533 & 51.97983 & 0.0971 & 40 \\
\hline
\end{tabular}

*Null Hypothesis: No residual autocorrelations up to lag 12.

Results of VAR Residual Heteroskedasticity Tests

\begin{tabular}{llllll}
\hline $\begin{array}{l}\text { Joint test: } \\
\text { Chi-square }\end{array}$ & df & Prob. & & & \\
\hline $\begin{array}{l}\text { 40.98059 } \\
\text { Individual components: }\end{array}$ & 0.0514 & & & \\
Dependent & R-squared & F(9,138) & Prob. & Chi-sq(9) & Prob. \\
res1*res1 & 0.142335 & 2.544665 & 0.0098 & 21.06558 & 0.0124 \\
res2*res2 & 0.068830 & 1.133401 & 0.3434 & 10.18681 & 0.3356 \\
res2*res1 & 0.071942 & 1.188625 & 0.3070 & 10.64744 & 0.3007 \\
\hline
\end{tabular}

*Null Hypothesis: No heteroscedastity

Results of VAR Residual Normality Tests

\begin{tabular}{lllll}
\hline Component & Skewness & Chi-sq & df & Prob. \\
\hline 1 & 0.332432 & 2.725937 & 1 & 0.0987 \\
2 & -0.134238 & 0.444492 & 1 & 0.5050 \\
Joint & & 3.170429 & 2 & 0.2049 \\
Component & Kurtosis & Chi-sq & df & Prob. \\
1 & 6.398967 & 71.24335 & 1 & 0.0000 \\
2 & 2.849454 & 0.139762 & 1 & 0.7085 \\
Joint & & 71.38311 & 2 & 0.0000 \\
Component & Jarque-Bera & df & Prob. & \\
1 & 73.96928 & 2 & 0.0000 & \\
2 & 0.584253 & 2 & 0.7467 & \\
Joint & 74.55354 & 4 & 0.0000 & \\
\hline
\end{tabular}

*Null Hypothesis: Residuals are multivariate normal 
Inverse Roots of AR Characteristic Polynomial

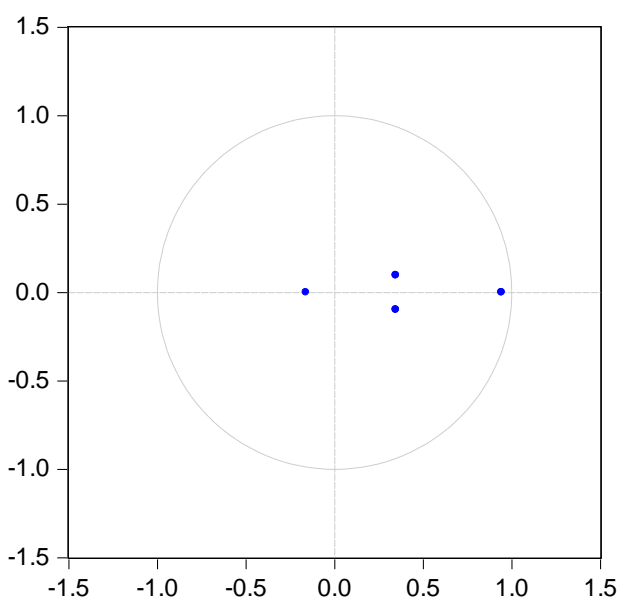

